\title{
The Effect Analysis of Online Reading and Writing on the Political Socialization Process of Adolescents
}

\author{
Young-Soo Lee ${ }^{1}$ \\ ${ }^{1}$ Professor, Dept. of Mass Comunications, Dong-guk University, Korea, lee.youngsoo@daum.net
}

\begin{abstract}
Since adolescents become adult citizens in the future and exercise sovereignty independently, the kind of political consciousness they have is closely related to the development of democracy in society. The ultimate goal of this study is to come up with effective directions and measures for youth's political socialization in order to cultivate correct political consciousness that can be the driving force behind the development of democracy. Furthermore, this study is aimed to examine the influence of media on the political socialization process of adolescents, rapidly taking place in our society. It empirically examined a series of processes by which young people acquire and exchange political information online, the online social capital they formed, and their political dialogue in the course of political participation. In-depth interviews were conducted among 20 teenagers participating as members of a specific community, such as Asunaro, a youth human rights behavior. The interviews were conducted using items extracted through big data as a question scale to observe adolescents' online reading and writing behavior. Also, it examined the political-related activities in the process of forming political-related perceptions and attitudes based on the study observation. As a result of the analysis, online media, especially online reading and writing behavior on social media was becoming a major channel to promote youth's political participation with affecting on the political participation of various types of youth. It was found that adolescents who have a high understanding of social issues and frequently talk about these with close people, such as parents and friends, freely discuss these, and actively participate in after school group activities. Young people were actively participating in politics in their own way, and they recognized their own political participation as a new type of politics that was opposed to the existing political participation methods of the older generation.
\end{abstract}

Keywords: Youth, Political Socialization, Social Capital, Political Participation, Political Behavior, Conversation, Big Data

\section{Introduction}

\subsection{Necessity of Research}

Political socialization refers to a series of processes in the members of society forming values and beliefs related to the political environment of their society and developing their political ego[1]. In addition, its microscopic level is the process of internalizing the political style, political culture, knowledge, values, and attitudes of individuals who are members of society[2], and the macroscopic level is the process of inheriting political culture between generations by conveying values to the next generation. From a micro level, the most important periods in the process of individual political and socialization are childhood and adolescence. One of the recent phenomena found in our society is that the youth's political socialization, or the youth's rapid interest and participation in real politics, is

Received: June 26, 2021; $1^{\text {st }}$ Review Result: August 15, 2021; $2^{\text {nd }}$ Review Result: September 28, 2021 Accepted: October 31, 2021 
increasing, and this phenomenon is occurring more frequently through the Internet. This can be said to be a phenomenon in which changes in our social and political environment and advances in the technological environment of the Internet are occurring in conjunction.

The Internet, characterized by interactivity, is not just a tool for acquiring information, but also serves as a space of forming public opinion where more people can participate. The concept of a public forum claimed by Habermas [3] does not only take place in physical spaces, but is also applied in online spaces through the Internet. In an online space, individuals compare and exchange their opinions with the other party, and form individual opinions and social public opinion through the process of coordinating and collecting opinions [4]. In this way, individuals can often access the process of acquiring, sharing, and exchanging opinions by interacting with others through online spaces.

Online posts, reading comments, and writing are actively used as tools for interactive exchange of opinions on Internet news sites. Posts and comments are actively used as online tools to express one's opinions on other people's writings or articles or to present additional information. In particular, comments can directly convey their thoughts through short articles and exert immediate influence over existing online writing. As such, online writing and reading act as tools to easily induce active participation of users and enable interactive online discussions[4][5]. Kim Soo-jung's family research[6] suggested variables such as "reading online posts/comments," "production of online political content," "acquisition of political information through SNS," and "online discussion" as factors that dramatize individual political attitudes.

As seen from the 2008 issue of mad cow disease and the 2016 presidential candlelight vigil, youth's political participation is very active in our society compared to the past. Adolescents often play a role as subjects of families, schools, churches, and various social groups. Therefore, depending on what kind of political consciousness they have, the development of democracy in these groups and the entire society based on these groups will be affected. In many cases, adolescents cannot participate in national decision-making as sovereign, but they often exercise their rights as decision-makers in their own living places such as home and school Internet meetings. Therefore, it can be said that the democracy of the affiliated group depends on what kind of political consciousness adolescents have.

Since adolescents become adult citizens in the future and exercise sovereignty independently, the kind of political consciousness they have is closely related to the development of democracy in society. This is because the political consciousness formed in adolescence often leads to the political consciousness of adulthood. Therefore, research on the relationship between political opinions and actual politicalrelated behaviors through the media will be of great academic and practical value at this time when youth's political participation, which remained among the underprivileged in the past, is remarkable. In particular, existing studies have been mainly conducted on ordinary citizens, and studies that closely examine the relationship between online political information exchange and actual political participation behavior of adolescents are still insufficient.

Therefore, this study aimed to (1) examine online media such as social media and SNS, focusing on political communication activities, and (2) explore the process of youth's political attitude and political socialization, social capital, and political participation.

\subsection{Purpose of Study}

This study attempted to examine offline political-related activities through political socialization in two aspects: political dialogue with neighbors, including family members, and actual performance of political-related activities. In other words, it examined whether active online exchange of political information leads to an increase in political-related conversations in real life and to actual actions. Existing studies have shown that individual political conversations have an important influence on actual political participation[7]. Individual political opinions are formed through exchanges of opinions 
between people and observations occurring in the process, and ambiguous opinions are gradually embodied as concrete and firm attitudes or voting actions[8]. Therefore, face-to-face political dialogue acts as an important factor in the process of political socialization.

This study attempted to empirically examine the process of youth's acquisition and exchange of political information online, the online social capital formed through this process, and their politicalrelated conversations in real life through political participation. To this end, this study observed adolescent's online reading and writing behavior, analyzed its contents, and investigated for actual political-related behavior based on this.

The ultimate goal of this study is to come up with effective directions and measures for youth's political socialization to cultivate correct political consciousness of youth that can be the driving force behind the development of democracy. In order to achieve the research purpose, this study proposed the following research questions and tried to prepare an efficient political socialization plan for adolescents suitable for the new political participation environment in our society.

Research Question 1: What role does adolescents play in their political environment and socialization?

Research Question 2: How does adolescents' online reading and writing affect formation of social capital?

Research Question 3: How does adolescents' online reading and writing affect political dialogue?

Research Question 4: How does adolescents' online reading and writing affect political participation?

\section{Theoretical Background}

\subsection{Youth's Political Participation and Political Socialization}

Political socialization can be understood from two main perspectives. One is for individuals to build their own political world by acquiring political-related attitudes, beliefs, and types of social behavior. This includes a series of processes of making value judgments and expressing intentions related to politics[9]. Another is the perspective that values the process of individuals acquiring political culture such as political system norms, attitudes, and actions in the current political environment and delivering them to the next generation[10].

Among them, what is of interest in this study is the political-related acts that adolescents in our society form and perform through political-related beliefs and attitudes. Here, political-related behavior means carrying out political-related conversations with people around them, including family members, and actual political-related participation. This study attempted to understand the political participation and socialization of adolescents in connection with the online media or the Internet.

Adolescents' political consciousness is formed by various media such as home, school, colleagues, mass media[11]. Youth is a sensitive period in the process of political socialization and is greatly influenced by the political culture of the time. The reason is that political culture is the totality of the political lifestyle from political community members.

Recently, political culture in Korea has shown a different pattern from the past along with the changes of the times. Young people expressed political interest with changed political actions starting online, such as the World Cup semifinals, "Roh-sa-mo" activities, the 16th presidential election, candlelight protests for the death of middle school girls, the mad cow disease scandal, and Choi Soon-sil's state affairs manipulation and presidential impeachment.

In particular, young teenagers who were politically indifferent are actively expressing political interest through online media, forming a different culture of political participation than in the past.

Nowadays, teenagers aim for an open community that values communication with individualism while using mobile and the Internet as their means of expression. A feature found in this process is the 
adolescents' active participation in online discussions[4]. Interest for the impact of online reading and writing on adolescents' political perceptions and behaviors is increasing since online discussions are based on reading and writing. Therefore, this study attempted to research the role of adolescents' online reading and writing behavior in the process of political socialization.

\subsection{The Influence of Online Reading and Writing}

One of the things to be considered in the discussion on media use and politics is how perceptions and actions of politics appear according to the characteristics of media. While traditional mass media deliver information one-way to users, new media such as the Internet allow users to play an active role in the process of information delivery and acquisition. Therefore, we can expect that even the same information varies depending on the transmitted path; the characteristics of the media used by the individual.

Internet use can show a difference from the use of traditional media since Internet itself has a strong participatory nature. Internet use is basically a highly involved act. Unlike mass media, there are various ways to express one's opinion through posting, commenting, "publishing," and online poll participation on the Internet.

In particular, political-related reading and writing online have great significance providing an opportunity for rational and critical discussions related to politics. Reading can contribute to enhancing social virtues, especially on citizenship, such as adherence to debate norms and tolerance[12]. In the end, cultivating reading skills and listening to other people's opinions in the Internet space can increase the possibility of realizing the ideal deliberative democracy. Specific reading and writing behaviors related to politics can contribute to the enhancement of civic virtues such as political learning, participation, and trust and tolerance[13].

Therefore, finding out how much information teenagers have read and written about politics in the Internet space is expected to play an important role in understanding the various effects of online "reading" and "writing" at this stage when the Internet has become a decisive space for civil political participation in our society. Teenagers have been alienated from political participation, but they can freely access and spread information related to politics through the Internet, and consequently form opinions, attitudes, and intentions on politics as a member of a democratic society. Through this process, reading and writing in the Internet space are expected to play an essential role in changing the class and function of traditional political participation and its meaning.

\subsection{Internet Use and Social Capital}

Social capital is a concept of encompassing the asset attributing inherent in social relationships that one individual and group have with another. What frequently appears in discussions related to social capital is the relationship between media and social capital. For example, Putnam[14] saw that media use reduces social capital and consequently reduces political participation. On the other hand, some media scholars saw that when a new communication method is introduced by the media and the connection increases between people, they become interested in political participation and the participation rate increases as well[15].

Since the advent of the Internet, discussions on social capital have developed into discussions on the impact of the Internet on existing social capital and the formation of new online social capital. Research results on the effect of the advent of the Internet on social capital are divided into social capital reinforcement theory, decline theory, and convergence theory. The theory of strengthening social capital is based on the fact that the Internet will have a positive impact offline by enabling connections between people with common interests and forming intimacy and trust between family, friends, and co-workers. 
The theory of social capital decline explains that the Internet causes social inequality due to the information gap, loss of face-to-face contact opportunities, and cyber division. However, Internet social capital convergence theory understands the Internet as an online-offline, private-public interest interaction space. It is believed that the social capital formed here should be interpreted as a new form of social capital[16]. This reflects the characteristics of the Internet social movement, to say, it is formed online, but eventually influences offline, and that the Internet is also used as a tool for public interests, although it is a space seeking personal interests.

The reason why youth discussions become important in online social capital discussions is that youth groups are the most active Internet users and in many cases, new relationships are formed through online meetings. The younger generation actively accepts new media compared to the older generation, showing a difference from other generations in how to use it.

The reality is that there has not been much discussion on the impact of Internet use, especially online reading and writing, on social capital formation. Although existing studies have shown that the relationship between online community formation and social capital is not necessarily negative[17], relatively little empirical verification has been made. This study attempted to investigate the relationship between reading, writing, and social capital, focusing on adolescents who are active participants in online reading and writing.

\subsection{Online Reading and Writing and Political Participation}

The Internet is relatively inexpensive and allows you to acquire a variety of information quickly. The mass media is often led by several specific broadcasts or newspapers, but there are numerous news sites, political communities, and bulletin boards online. One can look at the opinions of others coming up in real time, and can also interact through reading and writing[5]. Online activities are often known to be 'playful and self-expressing'[18]. For example, heavy topics such as politics are caricatured through parody and opinions are expressed in their own way. Existing studies have explained that this process will lead to a "long-term mobilization" phenomenon in which young people, who have been traditionally indifferent to politics, are active in political participation online and participate in offline politics in the long run[19].

Domestic research results generally report that acquiring political information through the Internet plays a positive role in political participation. For example, Kim Yong-chul and Yoon Sung[20] said that the use of political sites has a positive effect on voting participation. Similarly, Lee Won-tae[21] and Na Eun-kyung[22] reported that acquiring political information through online political communities, sharing political information, discussions, and conversations among netizens have a positive effect on political participation.

Since the 2002 presidential election, interest in political participation using the Internet has begun to increase. The Internet played a role in spreading political and social issues centering on the younger generation at that time. Similar cases were found in the 2008 mad cow disease wave and 2016 candlelight vigil[23]. At that time, it was not the older generation but the youth who led the early candlelight vigil. This can be said as an example of the fact that adolescents' online political reading and writing can lead to offline political participation.

\subsection{Political Dialogue and Political Socialization}

The factor that mediates the process in which online reading and writing form social capital and this social capital influences political participation again would be political-related dialogue with neighbors. Social capital is basically formed by relationships with people, and trust in them and social institutions acts as an important factor[24]. Therefore political dialogue with trusted people plays an important role 
in individual political participation. In a democratic society, public opinion on public issues becomes an essential requirement for citizens' political participation, and it is a political dialogue between individuals.

In fact, Rosace and Sha[24] found that political dialogue with people around them had a positive effect on political participation. In domestic studies, it was also found that acquiring political information and face-to-face conversations through the Internet have a positive effect on political participation offline and online[25].

When the act of acquiring political information is viewed as political participation in a passive sense, the acquisition of political information through face-to-face dialogue with the Internet can also be seen as one of the individual's political participation processes. Therefore, in this study, it was considered that online reading and writing related to politics, which are passive political participation, form social capital, which in turn leads to political dialogue with neighbors and ultimately leads to active political participation. Through this series of processes, it is believed that the youth's political participation and socialization occurs.

In this study, we intend to empirically review the process of political socialization presented through theoretical discussions so far with focusing on online reading and writing. In other words, this study recognized that adolescents are the leaders of the future political society and attempted to understand in what direction our society's political participation landscape will change in the future by conducting empirical verification of the impact of online reading and writing on the political socialization process.

\section{Research Method}

The research conducted through this study examines the effect of youth's online reading and writing on the youth's political and socialization process. To this end, 1) after observing the online reading and writing of adolescents to grasp their characteristics, 2) the political-related actions they perform in the process of forming perceptions and attitudes related to politics were examined. The role of online reading and writing in the process of youth political socialization was examined in this study. The research to be conducted in this study is largely 1) observation of online reading and writing, 2) observation of the process of forming online social capital, 3 ) and conversation related to offline politics and observation of political participation. Data were secured and analyzed using big data search analysis and in-depth interview methods step by step.

Google and social media were searched to analyze big data, and in-depth interviews were conducted with teenagers. In other words, this study tried to investigate the effect of online information exchange among teenagers on actual political-related behaviors focusing on 'reading and writing' related to politics occuring online. In addition, this study was intended to pay attention to the online social capital formed during the online information exchange process of adolescents and to examine the effect of such social capital on offline political-related behavior. Through this, this study tried to understand the political and socialization process of adolescents that is rapidly taking place in our society.

\subsection{Big Data Search Analysis on the Current Status of Youth's Political Reading and Writing}

Using Google's search trend, the factors of Korean adolescents' willingness to participate in politics were observed, and social capital formation, political-related dialogue, and political participation factors were analyzed. Google's search trend analyzes big data searching terms entered by users around the world and standardizes and provides the amount of searches entered by users in specific regions at specific times.

Therefore, this study extracted Google's search terms for teenagers used for social capital formation, political-related dialogue, and political participation during the general election and used the search 
volume from December 2019 to July 2020.

\subsection{In-depth Interview Investigation on the Effectiveness of Youth's Reading and Writing related to Politics}

The experience of reading and writing for youth's was investigated for the members of each community, and how this experience relates to the formation of social capital. How political-related perceptions, attitudes, and actions appear according to the experience of reading and writing were also examined. In-depth interviews were conducted among 20 teenagers participating as members of a specific community, such as Asunaro, a youth human rights behavior.

1) Subject to investigation

This study explored the current process of political socialization of adolescents by dividing adolescents into middle and high school groups and conducting in-depth interviews.

[Table 1] Overview of In-depth Interviews

\begin{tabular}{|c|l|}
\hline Category & \multicolumn{1}{c|}{ Outline of the survey } \\
\hline $\begin{array}{c}\text { Target of the survey In-depth } \\
\text { interviewees. } \\
\text { (20 students) }\end{array}$ & $\begin{array}{l}-10 \text { middle school students } \\
-10 \text { high school students. } \\
\text { (20 teenagers participating as members of a specific community, such as Asunaro, a } \\
\text { youth human rights behavior) }\end{array}$ \\
\hline Sampling methods & FGI survey \\
\hline Period of Survey & July 2020 - September 2020 \\
\hline Survey method & Complementary investigation (email and phone survey) after interview \\
\hline
\end{tabular}

2) Investigation tools

In order to construct the questionnaire, a questionnaire was prepared after conducting prior research analysis and preliminary interviews on youth political socialization with 10 people working in the Asunaro community consisting of youth and general adults. The main contents included the following.

[Table 2] In-depth Interview Key Questions

\begin{tabular}{|c|c|}
\hline Survey area & Questionnaire \\
\hline \multirow{4}{*}{$\begin{array}{l}\text { Adolescents' Perceptions toward } \\
\text { Political Socialization }\end{array}$} & Gender / Age / Grade \\
\hline & Definition of political socialization \\
\hline & Types and time of online media use \\
\hline & Purpose of using online media. \\
\hline \multirow{2}{*}{ Political conversation status } & Location of conversation /conversation time/conversation target \\
\hline & The reason of talk. \\
\hline \multirow{3}{*}{ Status of political participation } & Recognition status for the political issue and the path of recognition \\
\hline & Form of political participation using online media/ comments, bulletin boards, etc. \\
\hline & Period/ number of political participation with online media \\
\hline \multirow{3}{*}{ Social capital } & Formation of social capital \\
\hline & Recognition status for the function of social capital \\
\hline & Relationship/satisfaction with social capital and political participation \\
\hline
\end{tabular}

3) Research procedure

The survey of in-depth interview is an appropriate research method that can listen to the in-depth political participation and socialization of adolescents. By exploring the process of youth's online media use and political participation, it will be a useful way to enhance the reading and writing function of 
online media, achieve correct youth political socialization, and seek ways to participate in politics. Indepth interviews began in July 2020 and completed in September 2020. The target of in-depth interview were teenagers participating as members of a specific community, such as Asunaro, a youth human rights behavior. It was made up of voluntary participation of teenagers. The interview was conducted in a focus group method, and the researcher conducted the interview in person.

\subsection{Analysis Method}

The data analysis of this study was conducted in the following way.

(1) First, the article search method was used for online media from December 2019 to July 2020 using Textom, a big data related word search program.

(2) Secondly, Google's search trend was used to observe the formation of social capital, politicalrelated dialogue, and political participation factors for Korean youth's intention to participate in politics.

(3) For the categorization of data, the in-depth interview survey selected categories such as online media usage behavior(Device, usage, location, time), user characteristics(Period of usage, level of proficiency)., status and perception of political socialization, political dialogue status, and political participation status. Coding was performed after converting this to the coding category and analyzed the responses by description.

\section{Research Results}

\subsection{Search Results for Big Data related Words}

First, in order to create a questionnaire for FGI related to youth's political participation, the study extracted related words using big data through major portals such as Naver, Google, and SNS (Facebook, Instagram, and Twitter). For this extraction, a big data related word search program 'textom' was used. In particular, it is useful for network analysis by searching for data such as portal search sites Naver and Daum to provide related keyword rankings and data and providing matrix information according to the frequency of search keywords. This study collected data for eight months from December 2019 to July 2020 targeting the following news from Naver, Google, and Facebook.

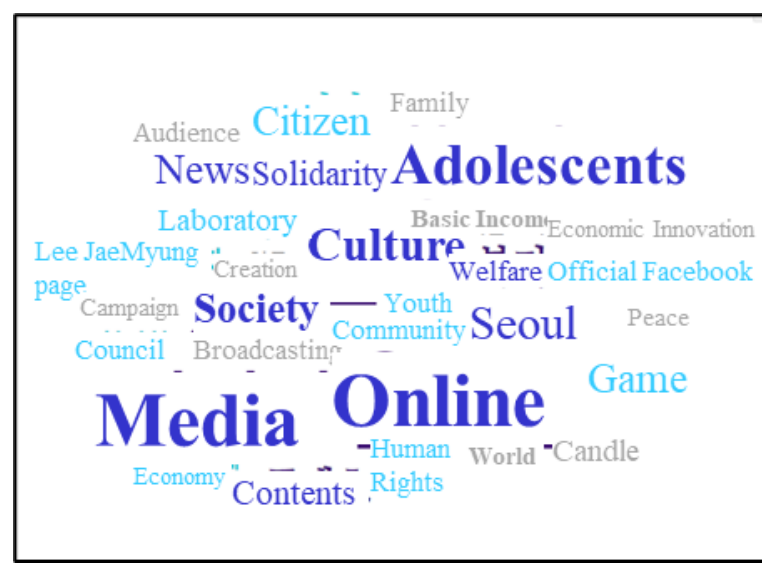

[Fig. 1] 25 Key Words, Word Cloud

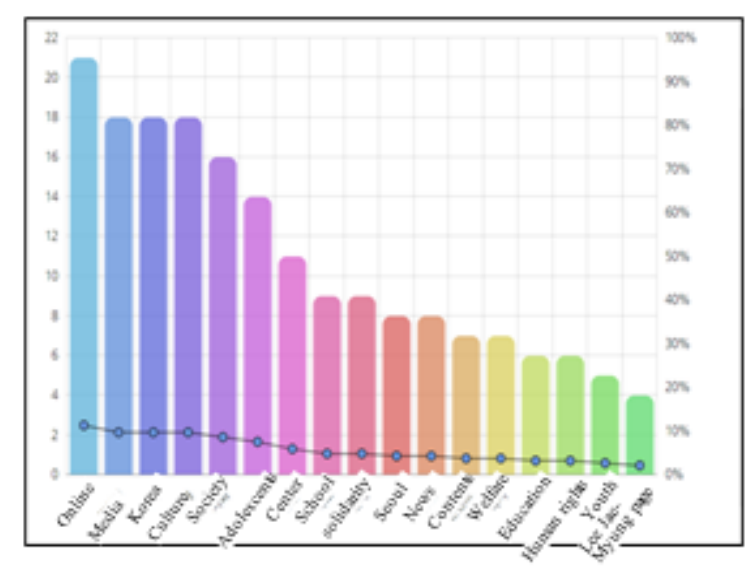

[Fig. 2] Barchart

Word cloud is a technique that visually highlights high-frequency core words so that you can intuitively grasp key words and concepts in documents. Among the 100 related keywords extracted by 
searching for related words through the collection list, 25 key words were selected and analyzed again in consideration of the frequency and importance of the word itself, and the word cloud in [Fig. 1] was created. The size of the letter indicates the size of the frequency. As shown in the graph of the results, it can be seen that many words such as "social," "youth," "economy," "human rights," "culture," and "welfare" were mentioned as search terms related to youth's political participation. The words "media" and "online" are mainly mentioned as channels that express opinions on them. Words such as "news," "solidarity," "youth," "broadcasting," "exercise," and "content" imply the context of political participation, suggesting "citizens" and "solidarity" as social networks that discuss social issues such as "economic innovation," "basic income," and "peace." It also shows that words that imply political activities such as "community," "council," "candles," and "world" are also mentioned on social media, an online network medium. [Fig. 2] is the result of a bar chart obtained by extracting the top 25 search terms.

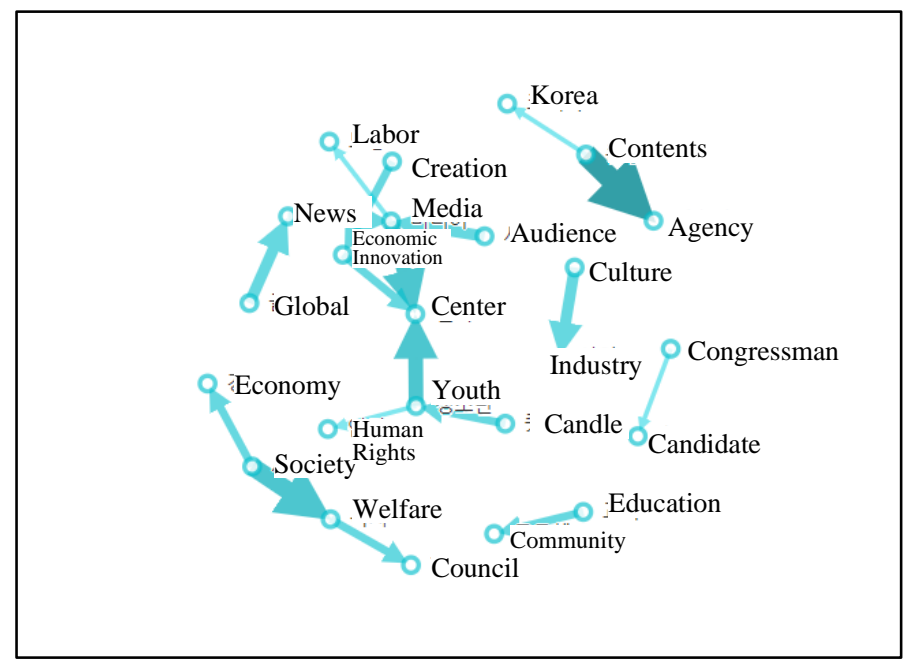

[Fig 3] Network of 25 Word Pairs

[Fig. 3] is a network graph of 25 word pairs. It is a visualization of 25 word pairs randomly selected in consideration of the importance of words among the co-occurrence word pairs of the upper frequency grouped based on the N-Gram value. The higher the frequency, the thicker the arrow. The direction of the arrow means that when A appears, B appears in series with a high frequency. As shown in the graph, the words "youth" and "media" are key words, dealing with the issues of "economic innovation" and "human rights." Discussions that develop the word "youth" as a key word are converging into words related to "candles" and "human rights." This suggests that youth's expression and participation in recent social issues are often mentioned in relation to candles and human rights. In addition, discussions are underway from the macroscopic point of view of 'social', and society is converging into social concepts in relation to 'economy' and 'welfare', and are connected to words suggesting a network of 'council'. Discussions unfolding with the word "media" as a key word are developing into discussions on social issues such as "economic innovation" and "labor," which are connected to words suggesting social networks such as "center" and "viewer."

In the end, looking at the results of the network graph, it can be seen that social issues such as economic innovation and human rights are being conveyed through the media in the current discourse on 'youth political socialization' in Korean society. The critical view of the issue can be explained as being actively developed through the social network in the form of social solidarity, leading to political participation such as "candles." 


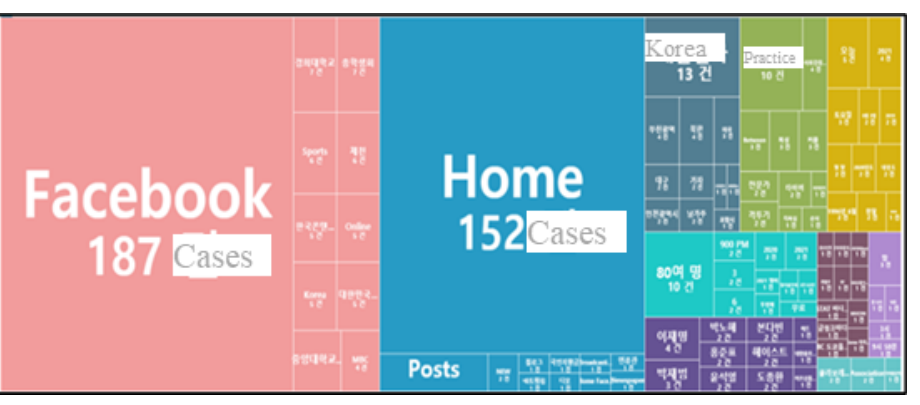

[Fig. 4] Identification of Individual Names

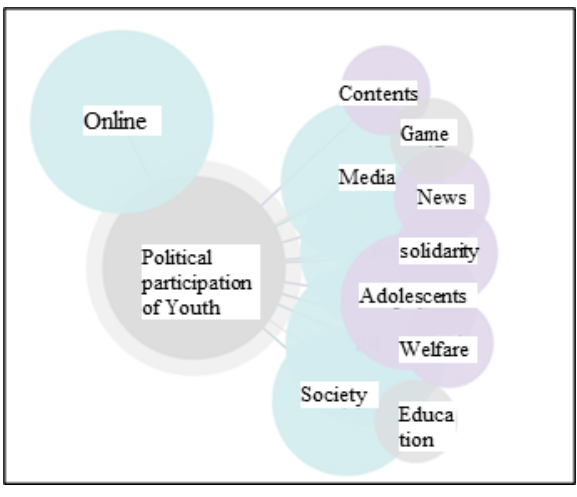

[Fig. 5] Preview Network

As shown in [Fig. 4], adolescents were using Facebook the most during the collection period, and home caused by COVID-19 was the next most recognized entity online. This shows that the media in which teenagers exchange political information is through online media such as major portals and SNS, and in particular, Facebook is the main media. The reason why YouTube, which has recently shown high utilization rates among teenagers, was excluded from this analysis is that the vast amount of unrefined data of YouTube, which is the characteristic of YouTube, was not suitable for analysis. According to the results of the preview network analysis in Figure 5, teenagers mainly exchange information on society, content, news, youth, education, and welfare through 'online media', especially social media such as Facebook, and acquire relevant knowledge from there. It is noteworthy that political perceptions and attitudes related to politics are being formed through social media, and political-related actions are being carried out in this process.

In order to construct a scale differentiated from the methodology used in previous studies as described above, question items related to the influencing factors on the political socialization process of adolescents were constructed based on big data analysis. This survey derived empirical results reflecting reality through FGI.

Based on the derived results, the main items of the questionnaire were set according to the goals of this study, and the question items were conceptualized and used for FGI.

\subsection{Adolescents' Online Reading and Writing Behavior and Motivation for Use}

\subsubsection{Adolescents' Online Reading and Writing Behavior}

As a result of in-depth interviews with teenagers, asking about the use of Internet comments a day, 10 out of 20 respondents answered that they write about two to four comments a day. Six out of 20 students who responded write more than 10 comments a day answered that they write 10 or as many as 30 comments a day. In addition, four other students answered that they rarely use one or more per day. Five out of 20 respondents voluntarily presented their opinions on social issues online, and seven teenagers were openly responding to other people's opinions.

Sites mainly used by teenagers to write comments were largely divided into Naver, Daum, and YouTube. Twelve out of 20 students used Naver, followed by 9 students using YouTube. However, there were many students who used Naver or YouTube at the same time, and among Naver, Daum, and YouTube, they responded that they wrote comments on personal blogs, cafes, and SNS. When asked about the type of social media currently in use, most respondents answered that they use Kakao Talk and Facebook.

"I usually use Facebook and Instagram, write comments on my friends' SNS, and sometimes use 
YouTube. Among YouTube videos, I watch mukbang(eating) programs, fashion, and makeup YouTube and leave comments, or write comments while looking at SNS of my favorite celebrity. (Student 1)

"I go into Naver News, read the headlines, and read the news. I sometimes leave comments. Before the comment function disappeared in the entertainment article section, I left a comment on the celebrity post." (Student 2)

"I use it a lot in news articles... I went to Naver and wrote a lot of news about one person protests or candles.I write comments on articles about the general elections these days". (Student 3)

"Activities done by teenagers on sites where they write comments" were largely divided into blog operation, cafe activities, and search, while bulletin boards where teenagers write comments were largely divided into news bulletin boards, SNS, YouTube, and cafes. Seven of the 20 teenagers who responded to the interview said they would leave comments on YouTube's video's good articles and guest books. Students who answered that they were writing comments on SNS such as Facebook responded that they were writing comments on their friends' SNS or that they were writing comments again on other people's SNS. In the case of news boards, they responded that they write a lot of comments on news articles related to entertainment and current affairs.

\subsubsection{Youth's Motivation to Read and Write Online}

The most common response for teenagers to write comments was "self-expression." They thought they could freely express their thoughts on the Internet and responded that they could know various opinions at the same time. In addition, the reasons for writing comments were divided into 'sympathy', 'nettiquette'(Internet+etiquette), and 'fun'.

"When I write comments about government policies, I think it's good to express your opinion. There's not much space for teenagers to participate. "I think it's good because middle and high school students can participate on the internet." (Student 1)

"The reason why I'm writing a comment is because I say my opinion, I think I'm wrong about the article, and the person who wrote the comment can say, 'What I thought is wrong,' and I can check 'I think I'm right.' (Student 2)

They responded that they write comments on 'nettiquette' when they scoop up posts or get information through search. One respondent said, "when I collect posts, I sometimes write comments with some kind of manners and scraps. It's okay to say and take them, but it's polite to take them without telling them or revealing the source" Also, regarding the reason for writing comments, he added "When I leave a comment, it's fun for the other person to leave another comment.

\subsection{The Effect of Youth's Online Reading and Writing on Political Dialogue and Political Socialization Process}

According to existing studies, adolescents who have a high understanding of social issues and frequently talk about social issues with close people, such as parents and friends, freely discuss social issues, actively participate in after-school group activities, and present their opinions online. It was found that going through online political dialogue had a strong influence on subjective evaluation of political behavior or actual political participation behavior [2].

Teenagers who participated in the interview also answered yes to the question of whether online media serves as a vehicle for enabling dialogue on political issues. In an online environment with enormous information, students encountered political issues while receiving customized information tailored to individual or individual needs, and students also expressed their thoughts or feelings in writing. In 
addition, the more comments adolescents read, the higher their knowledge of political issues tends to increase. These communication factors can be an important factor in the process of political participation and socialization.

"I'm usaully talking to my family, especially my friends, about political and social issues. Sometimes we have deep discussions, but most share feelings and thoughts about related issues. "(Student 1)

"I'm getting more and more opinions through conversations, so I'm confident that I can do better if I do it again later." I think I get to express my opinion more confidently. I have been watching TV news with my parents and discussing a little in these days. "I think I'm more interested in society than before." (Student 2)

"Every time I turn on the computer, I usually search online for political information, but I watch YouTube videos and Naver articles a lot, and I ask to Naver's intellectual questions in the form of comments." These days, I think I see a lot of issues that famous YouTubers put up. Watching the video, I think I end up uncritically accepting what I say there." (student 3)

"I think I can access political stories and issues online. In the case of students, they often don't care about politics. However, new information is uploaded in real time on social media, and you can talk about your thoughts simply and easily. Maybe that's why I wasn't interested in politics. Even if I go, I think I keep looking at Kakao-story or Facebook, which is often done by children, and I want to know more about it." (Student 4)

As a result of the interview, the more students who have access to SNS, the more political stories and issues they experience, and this continued to induce students' interest. In addition, it can be seen that such information becomes background knowledge, expressing one's thoughts directly on SNS, searching separately, and getting to know more about the issues of interest.

\subsection{The Effects of Adolescents' Online Reading and Writing on Social Capital}

Many teenagers who participated in the discussion thought that the network through online media can contribute to the expansion of human relations, but it does not function well in strengthening the depth and friendship with people who have formed existing relationships. Meanwhile, most of the respondents turned out to be centered on homogeneous exchanges in the network. Although $25 \%$ of respondents said it was a heterogeneous exchange, even in this case, it turned out that "when only adding friends, when offline meetings are premised," and "because they are seniors in clubs," they are all conditional. It can be seen that adolescents are passive in forming connective social capital because they prefer homogeneous networks. Adolescents seem to reflect peer culture-oriented characteristics, not topics or issues in forming human relationships. Although adolescents are likely to form potential social capital, it can be seen that the formation of participatory social capital is not sufficiently achieved due to the lack of interest in political issues and lack of information. On the other hand, it can be seen that increasing SNS followers/friends for direct or indirect show-off effect or mass-producing content that inflates and shows off one's positive appearance are often seen.

"I think we can easily get the information we want and easily interact with people of similar interests through human relationships formed online. However, I also believe that anonymity can change these advantages. Rather than actually meeting offline and having emotional exchanges, I think online exchanges will have a lower depth of the relationship. Even if the depth is low, I think the width of the relationship is rather wider because it is easy to meet people of similar tendencies or similar interests." (Student 1)

"Online media can easily connect with people who have the same opinion as you, but these systems 
have different opinions.I think it amplifies the confrontation. For example, although we made friends politically,If I show extreme tendencies, I think I can easily break off the relationship." (Student 2)

"Rather than accepting and acknowledging various opinions, it seems to be creating extremeization by gathering individual interests or political tendencies. Examples include the confrontation structure between women and men, which is common on social media recently, and the confrontation structure between progressive and conservative." (Student 3)

"I think SNS users tend to show pretentiousness rather than their honest self." (Student 4)

\subsection{The Effects of Adolescents' Online Reading and Writing on Political Participation}

Adolescents' use of online media affects their political consciousness and behavior. The 20 students interviewed said they had changed their consciousness through political issues and stories through online media, and 14 of them said they had changed not only their consciousness but also their behavioral aspects such as actively expressing and practicing their intentions.

The recent emergence of social media has changed the concept of participation to a very different aspect from the traditional form. Participation activities on social media have the potential to expand to various forms, such as posting political messages and sharing videos/images, sometimes offline. In addition, for adolescents, political participation has a fairly wide spectrum. Voting, party activities, and participation in rallies are defined as political participation, while broad-sounding concepts include political participation in specific social issues such as watching political YouTube/podcasts, commenting on news articles, pressing Facebook likes, retweeting, hashtag (\#) movements, and sponsorship activities through direct or indirect consumption. Adolescents also responded that they are participating in politics in a much more diverse way than in the past and that interest in politics is also increasing. As a result of asking about the experience of participating in social activities through social media over the past year, it was found that they had experience in leaving opinions on social issues (posting, comments, civil complaints, etc.), posting scraps/retweets, and online signature movements.

"We only talk to each other when there is an online discussion or an online meeting, so I think it's difficult to influence political and social participation. These days, teenagers seem to be influenced by political issues through YouTubers. (Student 1)

"Since political and social issues are dealt with more often and more often online than offline, I think human relations formed online have the greatest impact on political and social participation. I think smartphones are the most accessible and used by people in modern society, which has a huge impact on political and social participation because access to online is easier than ever." (Student 2)

"When it comes to political participation, it doesn't necessarily mean voting or political activities, and I just think of seeing things on the Internet, writing comments, and talking to people who have similar tendencies with me." (Student 3)

"When I look at my friends around me, there are friends who participate in vigils and candlelight protests, and I also participated because of that atmosphere, but since then, I think I've gained more political interest (student 4).

"I participated in the candlelight vigil in Gwanghwamun about twice with my parents and enjoyed songs and performances. Social issues, for example, saw news related to COVID-19, commented on the Korean Peninsula, responded to surveys and participated in discussions at school. (Student 5)

"I mainly participated in hashtags campaigns using Instagram or petitions at the Blue House because it is most effective in making the issue an issue easily..." In the case of Blue House petitions, detailed answers to each question can be checked in a relatively short period of time, so I tend to participate a lot." (Student 6)

"I think reading political information on online news can increase interest in politics. In view of a 
member of the National Assembly who has recently been on the verge of amnesty due to his/her child's drinking and assaulting police officers. Also, seeing that the former Minister of Justice's suspicion of enrolling children affects the entrance examination system, I think Internet comments and interest have a great impact on the political society (Student 7).

\section{Conclusions}

This study examined a series of processes in which adolescents acquire and exchange political information online, and through online social capital and political-related conversations taking place through political participation. To this end, the researchers observed their online reading and writing behavior for adolescents, and based on this, we looked at the political-related actions they perform in the process of forming perceptions and attitudes related to politics.

As a result of the analysis, the characteristics found in the process of youth political socialization in our society are as follows.

First, many existing studies have found that media use and conversation have a political impact together. The use of hard news through newspapers, broadcasting, the Internet, and social media can have the effect of promoting political knowledge and promoting efficacy and participation. This is because the use of news becomes a resource for political dialogue, recognizes community problems, and provides opportunities for participation. As shown in the results of this study, The act of sharing information with people with similar perspectives through blogs or SNS is also changing the relationship between political dialogue, knowledge, efficacy, and participation. The role and importance of connection, communication, and conversation online, especially on social media, increase. Situations in which one can actively present one's opinions through online reading and writing can have differentiated cognitive and behavioral effects. In addition, communication through various methods is contributing to political participation in an online environment, including social media in which many people share not only messages but also images or videos.

Second, online media has been found to have an effect on the political participation behavior of various types of youth, making it a major channel for youth to participate in politics. The Internet is also a space for teenagers to realize new political practices and identities. Teenagers meet new friends through the Internet, build new networks, and form new identities. They are also exchanging information on public issues through the Internet and talking about major issues in society. The Internet is playing a role in providing a more useful venue for participation among teenagers. Therefore, by strengthening the online network of teenagers through this, the communication network can be further strengthened as a forum for public opinion to claim their rights. The development of networks through various media platforms, including the Internet, is an important means of accelerating the development of participatory democracy by providing dynamic communication spaces for teenagers.

Third, in expressing public opinions on social issues, knowledge of issues and the frequency of conversations on social issues in online spaces had a significant influence. However, offline conversations with friends seem to have the greatest influence on political participation than networks formed online. It can be seen that peer groups play a very important role in the political and socialization of youth. Overall, it can be said that the empathy and ripple effect on social and political issues are enormous in peer groups where friends and seniors can freely talk about political and social issues. Meanwhile, while teenagers were somewhat hesitant to publicly present their opinions, teenagers participating in after-school group activities, such as Asunaro members who responded to the study, were actively speaking on social issues. Such experiences of various participatory activities seem to provide adolescents with opportunities to recognize their identity as members of civil society and to actively act for the development of the community.

Through the results of this study, it is expected to understand whether their use of media remains 
individual-level effects or extends to social-level effects by examining the relationship between media use characteristics and political participation of adolescents in our society. Thus we can expect that adolescents' use of online media will be able to contribute academically to related fields by looking at the process of ultimately leading to political participation. In addition, this study is meaningful in that it is possible to observe the characteristics found in the process of youth political and socialization in our society and predict the political and social characteristics of our society in the future based on this stydy.

The limitations of this study are as follows. In the follow-up study, an integrated empirical verification process is needed by conducting multi-layered (hierarchical linear) model analysis of youth political socialization factors, social capital formation, political-related dialogue, and intergroup structural model analysis of political participation factors. Attempts should be made to understand the characteristics of each group in terms of media-related tendencies, SNS and characteristics of smartphone usage, political participation by type, and to analyze the causal relationship of these variables in depth.

This study is an exploratory study to use items extracted through big data as a measure. Although there have been existing studies related to youth's participation in politics, it can be a methodological contribution that can construct survey scale items through big data analysis and to understand youth's political conversations on portals and SNS. In addition, this study is thought to be useful in enhancing the reading and writing function of online media and seeking ways to participate in politics by exploring the actual use of online media and political participation of teenagers.

\section{Acknowledgments}

This work was supported by National Research Foundation of Korean Grant founded by the Korean Government(NRF-2018S1A5B5A07073902)

\section{References}

[1] H. H. Hyman, Political socialization: A study in the psychology of political behavior, The Free Press, (1959)

[2] G. A. Almond, S. Verba, The Civic Culture: Political Attitudes and Democracy in Five Nation Princeton, Princeton University Press, (1963)

[3] J. Habermas, The structural transformation of the public sphere: An inquiry into a category of bourgeois society, Cambridge: MIT Press, (1989)

[4] E. M. Kim, S. Yang, The Effects of Online Networks and Internet Literacy on Adolescents' Online Participation, Korean Journal of Journalism \& Communication Studies, (2017), Vol.61, No.3, pp.121-154, DOI: 10.20879/kjjcs.2017.61.3.004

[5] M. S. Lee, K. H. Yoo, Relationship between using comments and social participation: Focusing on users' willingness to participate in society according to whether to read or write comments, The conference of the Korean Speech \& Communication Association, pp.10-14, (2015), May 30; Seoul, Korea.

[6] S. J. Kim, Y. G. Cheong, Influence of Political Orientation, Use of News Media and Political Conversation on Political Participation Attitude and Behavior: Focusing on Impeachment of Park Geun-Hye, Korean Journal of Journalism \& Communication Studies, (2017), Vol.61, No.5, pp.69-101, DOI: 10.20879/kjjcs.2017.61.5.003

[7] W. S. Song, A study on differences of adolescents' political socialization based on family communication patterns, Studies on Korean Youth, (2018), Vol.29, No.2, pp.69-96, DOI: 10.14816/sky.2018.29.2.69

[8] E Katz, On parenting a paradigm: Gabriel Tarde's agenda for opinion and communication research, International Journal of Public Opinion Research, (1992), Vol.4, pp.80-86.

[9] L. A. Froman, Personality and political socialization, The Journal of Politics, (1961), Vol.23, No.2, pp.341-352, DOI: 
$10.2307 / 2126709$

[10] R. Sigel, Assumptions about the learning of political values, The Annals of the American Academy of Political and Social Science, (1965), Vol.361, No.1, pp.1-9, DOI: 10.1177/000271626536100101

[11] Y. W. Lee, S. T. Ha, A Study on the Political Communication Among Adolescents by the Type of Communication and Its Impact on Political Participation, Locality \& Communication, (2015), Vol.19, No.1, pp.221-247.

[12] N. M. Shin, H. S. Ahn, An analysis of Adolescents' media literacy: How do they read, write, and enjoy information and communication media?, Journal of the Korea Academia-Industrial cooperation Society, (2013), Vol.14, No.8, pp.3777-3785, DOI: 10.5762/KAIS.2013.14.8.3777

[13] E. M. Kim, J. W. Rhee, Rethinking 'Reading' online: The Effects of online Communication, Korean Journal of Journalism \& Communication Studies, (2006), Vol.50, No.4, pp.65-94, UCI: G704-000203.2006.50.4.007

[14] R. D. Putnam, Tuning in, tuning out: The strange disappearance of social capital in America, Political Science and Politics, (1995), Vol.28, No.4, pp.664-683, DOI: https://doi.org/10.2307/420517

[15] W. Rash, Politics on the Nets: Wiring the Political Process, W. H. Freeman, (1997)

[16] T. H. Sander, E-associations? Using technology to connect citizens: The case of meetup.com, Proceeding of Annual meeting of the American Political Science Association, (2005), September 4; Washington, DC.

[17] Y. J. Lee, H. Y. Yoo, An Analysis of the Linkage Between Social Capital, Political Interests, and Political Participation - From the Perspective of the Youth Facebook Network Structure -, Theory and Research in Citizenship Education, (2016), Vol.48, No.1, pp.139-166, DOI: 10.35557/trce.48.1.201603.006

[18] S. J. Lew, H. W. Lee, W. T. Lee, Political Use of Internet and Political Participation: media usage and voting behavior of Korean University Students in 2004 17th General Assembly Election, National Strategy, (2005), Vol.11, No.3, pp.141-169, UCI: G704-000434.2005.11.3.002

[19] P. Norris, A virtuous circle: Political communication in postindustrial societies, Cambridge University Press, (2000)

[20] Y. C. Kim, S. Y. Yoon, Political Use of the Internet and the 16th National Assembly Election, Korean Political Science Review, (2000), Vol.34, No.3, pp.129-147.

[21] W. T. Lee, A Study on Internet Political Participation: Focusing on the 17th General Election in Korea in 2004, Sogang University Graduate School, Ph.D dissertation, (2004)

[22] E. K. Na, G. H. Lee, H. S. Kim, Social Implication of Reading/Writing Online Comments(Replies) in Representative Democracy: Internet News Comments(Replies), Political Trust, Media Trust,and Political Knowledge, Korean Journal of Journalism \& Communication Studies, (2009), Vol.53, No.1, pp.109-132, UCI: G704-000203.2009.53.1.013

[23] J. S. Park, A Study of the Political Attitudes and Behaviors among Teenagers on the Candlelight Vigils in 2016, Journal of Learner-Centered Curriculum and Instruction, (2017), Vol.17, No 9, pp.495-514, DOI: 10.22251/jlcci.2017.17.9.495

[24] H. Rojas, D. Shah, Media use, political talk and social capital, Proceeding of the annual meeting of the American Association For Public Opinion Association, (2005), November 20; Florida, USA.

[25] J. S. Lee, Y. S. Lee, Research Examining Factors Affecting Individuals' Intention to Participate in Political Activities, Korean Journal of Journalism \& Communication Studies, (2009), Vol.53, No.5, pp.316-339, UCI: G704000203.2009.53.5.017 